\title{
MPROVED SINGLE-FACE LAPPING BY USING AN AIR BEARING SUPPORTED LAP
}

\author{
Gabriel Ascanio ${ }^{a}$, Carlos Cava ${ }^{a}$, Ricardo Chicurel ${ }^{b}$, Roberto Reséndizc \\ ${ }^{a}$ Centro de Ciencias Aplicadas y Desarrollo Tecnológico, Universidad Nacional Autónoma de México, Mexico, D.F. \\ Instituto de Ingeniería, Universidad Nacional Autónoma de México , Mexico, D.F. \\ ${ }^{\mathrm{c}}$ Pirámide Estructural del Golfo, Coscomatepec, Veracruz, Mexico \\ Centro de Ciencias Aplicadas y Desarrollo Tecnológico, \\ Universidad Nacional Autónoma de México \\ Circuito Exterior, Cd. Universitaria \\ 04510, D. F. México \\ Tel: +55-52-56228602 Ext. 1219 \\ Fax: $+55-52-56228620$ \\ E-mail: gabriel.ascanio@ccadet.unam.mx
}

\begin{abstract}
Lapping is a finishing process extensively used in the engineering world for those parts that require a fine finish surface such as gage blocks or flats for checking production parts. Nowadays, there are several machines in which single-face, double-face or rotating lapping processes can be carried out. Generally, all these machines use a rigid bearing system for supporting the lap shaft and a flexible coupling to connect that shaft to the motor. Therefore, their vibrations can affect the surface finishing of parts to be lapped. One way to reduce that effect and greatly improve the surface quality is to use an air bearing. The present work is aimed at investigating the lapping parameters when using an air bearing system. For comparison purposes, tests using a conventional rigid system were also conducted. Results show vibrations have a negative effect on flatness and roughness, reason for which lapping can take longer time to reach the same results obtained with an air bearing system.
\end{abstract}

KEY WORDS: Air bearing, single-face lapping

\section{INTRODUCTION}

Lapping is an abrasive process carried out by means of loose abrasive in which the role of the cutting points is played by grains finding momentary support on the laps. Lapping has four main purposes: to obtain superior accuracy as to dimensions, to correct shape imperfections, to obtain smooth polished surfaces and to improve the fit between surfaces. Seating valves in gas engines is a common illustration of lapping, with the valve itself serving as the lap.

The purpose of using a pneumatic bearing is to damp out vibrations that can introduce a negative effect on the surface quality. No reports of the application in lapping machines were found in the literature hence the concept appears to be novel.

Lapping is considered as a low rate removal process that is carried out by rubbing the surface to be lapped against a mating form called a lap. Three properties are taken into account when a part is going to be lapped. The first one is related to hardness, giving rise to the first lapping rule: "the lap must be softer than the workpiece"[3]. The second one refers to the pressure on the workpiece in order to assure contact with the lap. The last one refers to the kinematics of the relative motions between all the elements.

The lap may be charged with a fine abrasive moistened with oil or grease. If a part is to be lapped to a final accurate dimension, a mating form of a softer material such as close-grain cast iron, copper, brass 
or lead is made. Aluminum oxide, silicon carbide, and diamond grits are used for lapping. Lapping is a material removal process similar to grinding. However, lapping requires considerable time to achieve higher surface finish specifications, in most cases more than 100 hours, depending on the lap and parts to be lapped. The material removal rate for a lapping process is lower than that for a grinding process. Material removal rates less that $5 \mu \mathrm{m} / \mathrm{min}$ have been reported [4]. No more than 5 to $13 \mu \mathrm{m}$ should be left for removal by this method. For most applications, grit sizes range from 100 to 800 , depending on the finish desired. For most efficient lapping, speeds generally range from 150 to $240 \mathrm{~m} / \mathrm{min}$ with pressures from 7 to $21 \mathrm{kPa}$ for soft materials and $70 \mathrm{kPa}$ and higher for harder materials [2].

\section{DESCRIPTION}

In the rotating lapping machine discussed in this paper, a rigid structure supports the mechanism and the drive system, which consists of the lap, the pneumatic bearing and the motor. The lap used in this equipment is a $304.8 \mathrm{~mm}$ (12 in) diameter and $19 \mathrm{~mm}(0.75 \mathrm{in})$ thick plate made of ASTM 30 soft cast iron [5] and the conditioning rings are cylinders of $114 \mathrm{~mm}$ in diameter made of ASTM 4140 steel. The composition of the cast iron is $3.25 \% \mathrm{C}$ and $2 \% \mathrm{Si}$ with an average hardness of $210 \mathrm{H}_{\mathrm{RB}}$. A soft material is used in accordance with the fact that the lap should always be softer than the material to be lapped in order to avoid charging the work piece and cutting itself [2]. Harder laps will often cause glazing and scratching while laps which are too soft cause a loss of flatness and parallelism and will produce grayer finishes. Care was taken to make the plate heavy enough so that it would not distort in use. In order to allow the abrasive fluid to flow, angular and radial grooves were machined and the surface was rectified. Workpieces to be lapped are supported by three holders mounted over the lap at $120^{\circ}$ between them. The frictional force can be varied using weights mounted on the workpiece holders. In this prototype, the abrasive and liquid are manually supplied.

The pneumatic bearing consists of two complementary conical parts. This geometry allows axial and radial loads in the same plane. The pneumatic bearing has two elements: a static (lower) one and a floating (upper) one [3]. The static element of the pneumatic bearing has twelve spreads: six for the axial thrust component and six for the radial force component. The dynamic part, also called the floating element, has a conical surface and a hole in which the shaft couple to the gearbox is connected. The clearance between the two elements is $28 \mu \mathrm{m}$, when pressurized air is introduced at $490 \mathrm{kPa}$.

The drive system consists of a $373 \mathrm{~W}(1 / 2 \mathrm{hp})$ 4-pole induction motor coupled to a gearbox with a 5:1 reduction ratio, thus the maximum rotational lap speed is $350 \mathrm{rpm}$. In order to adjust the speed for optimum lapping, a frequency changer is directly connected to the motor. Normally, lapping equipment operates at a fixed lapping speed which is of the order of $250 \mathrm{rpm}$ [2]. Other operating conditions that were varied to determine their effect on the stock removal rate $[4,5]$ are the abrasive size and lapping pressure. Figure 1 shows a diagram of the rotating lapping machine and the conical air bearing. 


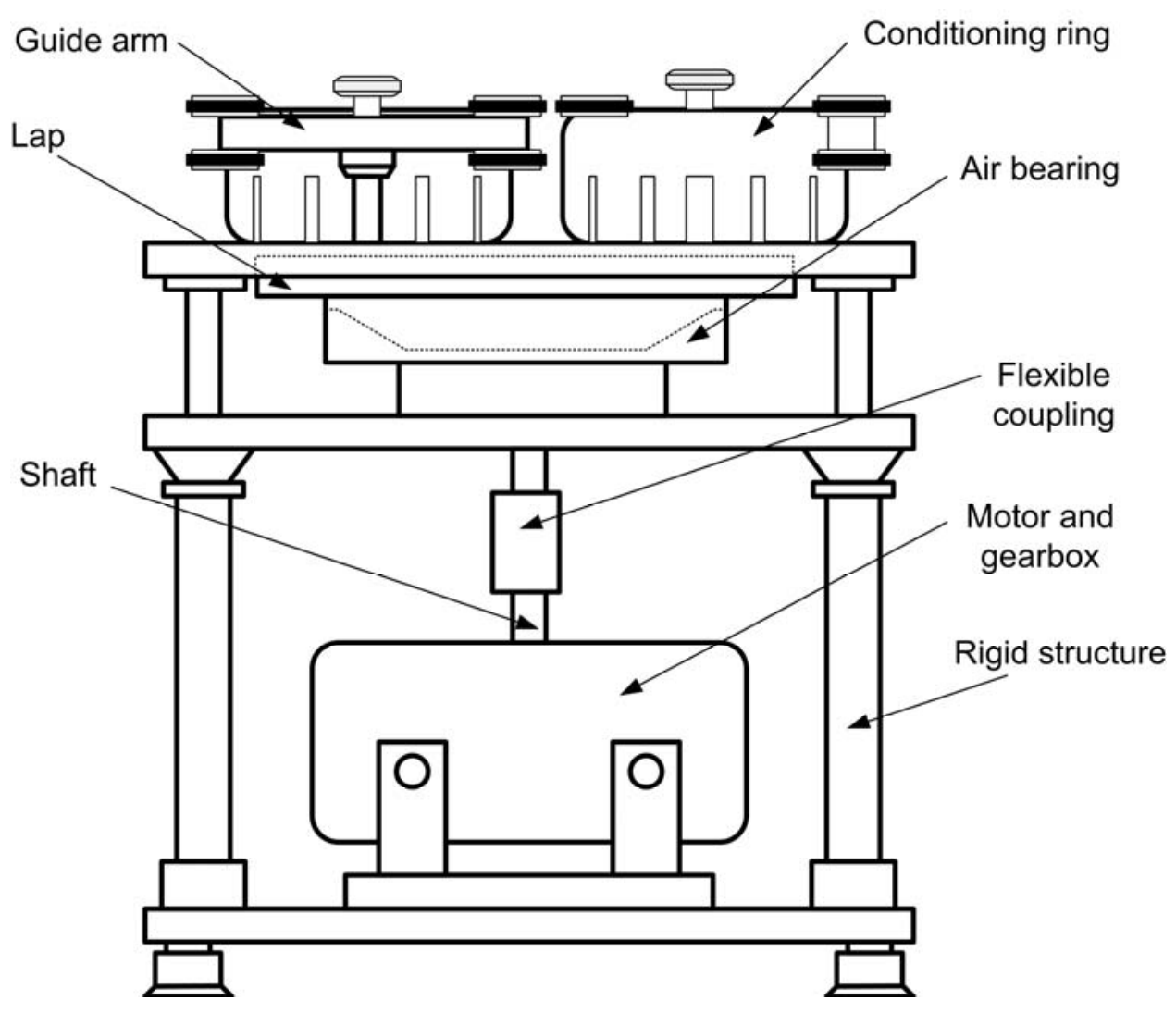

Figure 1. Rotating lapping machine with a pneumatic bearing.

\section{MATERIALS AND METHODS}

The test plan was divided into two parts. In the first one, lapping parameters when using an air bearing supported lap were studied. Tests were conducted using workpieces made of AISI 1045 steel of 12.2 $\mathrm{mm}$ diameter and $7.0 \mathrm{~mm}$ height, which were quenched and annealed so that and average hardness of $50 \mathrm{H}_{\mathrm{RC}}$ was obtained. Both sides of these workpieces were surface grounded, which allows starting the tests with a roughness number of 7 , equivalent to $6.3 \mu \mathrm{m}$. In the second part, a number of tests were performed to examine the effects of a rigid bearing on the surface quality compared to those obtained with an air bearing system. Rings made of AISI 4140 steel of $88.9 \mathrm{~mm}$ (3.5 in) outer diameter, $38.1 \mathrm{~mm}$ (1.5 in) inner diameter and $19 \mathrm{~mm}$ (0.75 in) were used. These rings were also quenched and annealed so that an average hardness of $46 \mathrm{H}_{\mathrm{RC}}$ was obtained. After that, they were surface grounded to $6.3 \mu \mathrm{m}$.

The abrasive compound for all the tests consisted of two parts: abrasive and vehicle. Calcined aluminum oxide was used as abrasive. In order to assess the effect of the grain size on the surface quality, abrasives no. $12(5 \mu \mathrm{m})$ and no. $13(1 \mu \mathrm{m})$ were chosen taking into account the hardness of materials to be lapped. On the other hand, machine oil MOBIL DTE-26 was used as vehicle since it is a light oil that dilutes easily the abrasive and allows having a uniform layer on the surface that remains adhered for a long time. One part of abrasive and 15.85 parts of oil by weight were carefully mixed and this concentration was kept constant for all the tests.

Tests were conducted at a lap rotation speed of $300 \mathrm{rpm}$ and three different pressures were used: 39.2 $\mathrm{kPa}, 98 \mathrm{kPa}$ and, $157 \mathrm{kPa}$. The lapping times for abrasive no. 12 were 30,60 and, 120 minutes while for abrasive no. 13 the times were 60,120 , and 240 minutes. 


\section{RESULTS}

\subsection{Air bearing system}

\subsubsection{Pressure and lapping time}

In order to determine the amount of stock removed, workpieces were carefully weighted before and after lapping. Figure 2 and 3 illustrate the stock removal amount as a function of lapping time for the two different aluminum oxide grain sizes, respectively. From figure 2 , it can be observed that this amount is greater when lapping at high pressures combined with long times, which is convenient for the first lapping stages. A similar behavior is observed in figure 3; however, the stock removal is considerably smaller for a $1 \mu \mathrm{m}$ grain size than that obtained with a $5 \mu \mathrm{m}$ abrasive grain size. It is also observed that, for low pressures, the amount of stock removed correlates linearly with lapping time.

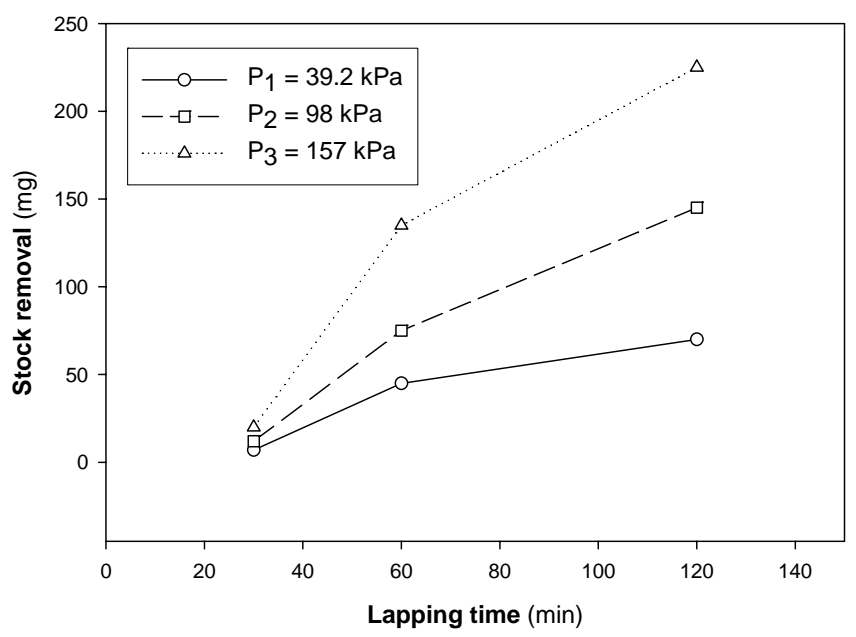

Figure 2. Stock removal as a function of lapping time for aluminum oxide no. 12 (machine with pneumatic bearing).

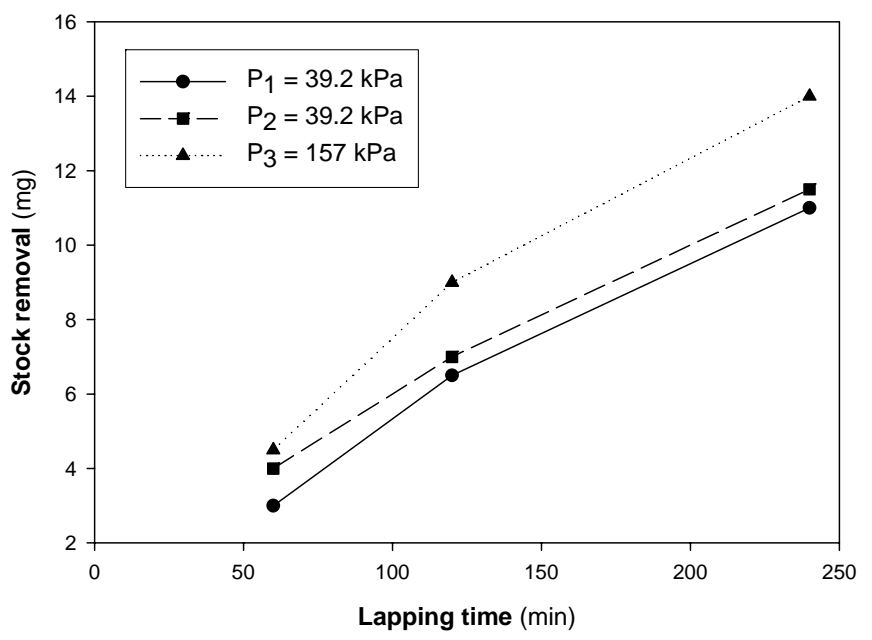

Figure 3. Stock removal as a function of lapping time for aluminum oxide no. 13 (machine with pneumatic bearing). 


\subsubsection{Roughness}

Surface quality was evaluated in terms of roughness, for which a stylus surface analyzer was used. The mean height of profile irregularities (Rc) was measured considering 5 points (profile peaks and valleys) over the sampling length. Figures 4 and 5 illustrate roughness Rc as a function of lapping time with aluminum oxide no. 12 and no. 13 as abrasives, respectively. From figure 4, when using abrasive no.12, it can be observed that the surface quality tends to improve when increasing lapping time, but it is clear that a low pressure gives better control on the workpiece roughness, which is very useful for the final lapping stages; however, in this case a longer lapping time is required. On the other hand, with abrasive no. 13, it is observed that the higher lapping pressures result in lower roughness. From figure 5, low pressures require very long lapping times for removing marks from grinding. Also, in this case, roughness decreases with increasing lapping times no matter what pressure is used. The best surface quality was obtained for the highest pressure and the lowest grain size for a 240 min lapping time. The measured roughness in this case was $0.5 \mu \mathrm{m}$.

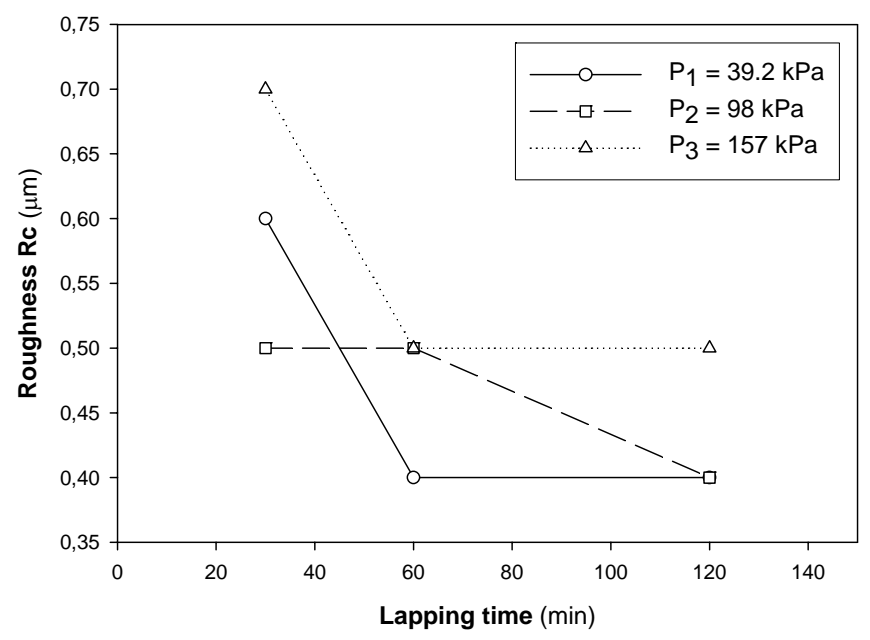

Figure 4. Roughness Rc as a function of lapping time for aluminum oxide no. 12 (machine with pneumatic bearing).

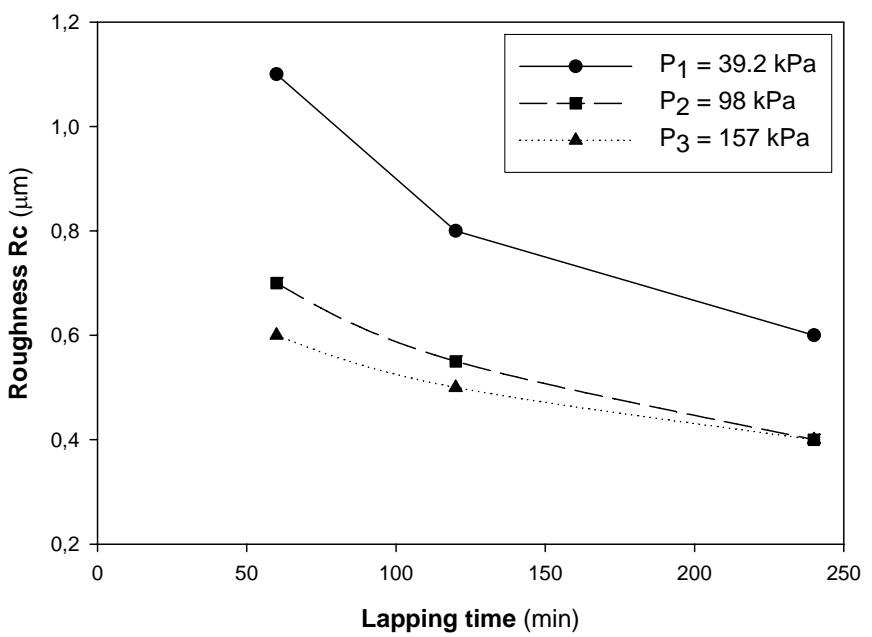

Figure 5. Roughness Rc as a function of lapping time for aluminum oxide no. 13 (machine with pneumatic bearing). 


\subsubsection{Step lapping}

Step lapping tests in which surface ground workpieces were first lapped with a $5 \mu \mathrm{m}$ grain size abrasive and then with a $1 \mu \mathrm{m}$ abrasive were conducted. Lapping pressure as well as the fluid abrasive concentration and the lap speed were kept constant. The process time was $240 \mathrm{~min}$. The best surface quality was obtained when working at $157 \mathrm{kPa}$ pressure, for which a roughness Rc of $0.1 \mu \mathrm{m}$ was measured. Figure 6 shows the surface images of the sequence used in this test for the best quality obtained. Marks from grinding are clearly observed in figure 6 (a), but after lapping with $5 \mu \mathrm{m}$ grain size they are partly removed in 6 (b) and, finally, a smooth surface is obtained for the final stage in 6 (c).

\subsection{Rigid bearing vs. air bearing}

\subsubsection{Roughness}

Surface ground workpieces were lapped using both systems: air bearing (lapping type A) and rigid bearing (lapping type B). In both cases, the total lapping time was 4 hours. During that period, roughness measurements were taken every 30 minutes, at which times the workpieces and the lap were cleaned in order to remove all the metallic particles released by abrasive action. The lap rotation speed was fixed at $300 \mathrm{rpm}$ and the pressure applied to the workpiece was due to its own weight. Figure 7 presents roughness Rc data with a cutoff of $0.25 \mathrm{~mm}$ as a function of lapping time with both $1 \mu \mathrm{m}$ and $5 \mu \mathrm{m}$ grain size abrasive. A difference of $0.5 \mu \mathrm{m}$ is observed at $30 \mathrm{~min}$ for both abrasives. On the other hand, this difference is smaller, between $1.0 \mu \mathrm{m}$ and $0.2 \mu \mathrm{m}$ for longer lapping times. As this figure shows, longer process time is required with a rigid bearing than with an air bearing to reach similar roughness levels.

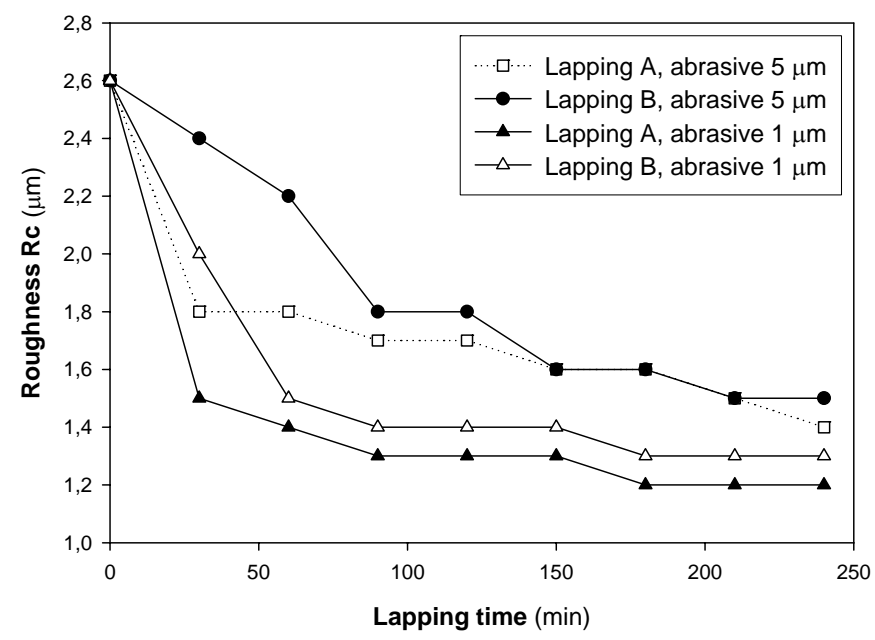

Figure 7. Air bearing vs. rigid bearing roughness comparison.

\subsubsection{Flatness}

Workpieces were lapped during 4 hours with aluminum oxide no. 12. Flatness was measured by means of a coordinate measuring machine Zeiss MC 850. For that purpose, a mesh with a $10 \mathrm{~mm}$ distance between nodes was traced on workpieces and the relative heights between a reference point and the others were then measured. Table 1 presents the results from the flatness tests. A smaller angular deviation in both planes is observed when vibrations are damped out.

Also, a smaller distance between the highest and the lowest points is observed with the use of an air bearing system. 


\begin{tabular}{|c|c|c|c|c|c|c|c|}
\hline \multirow{2}{*}{$\begin{array}{l}\text { Lapping } \\
\text { type }\end{array}$} & \multirow{2}{*}{\multicolumn{2}{|c|}{ Angular deviation }} & \multicolumn{5}{|c|}{ Topography } \\
\hline & & & Points & Standard & Maximum & Minimum & Maximum \\
\hline \multirow[t]{2}{*}{ A } & $X / Z$ & $0.0051^{\circ}$ & \multirow{2}{*}{32} & \multirow{2}{*}{1.1} & \multirow{2}{*}{-1.5} & \multirow{2}{*}{2.0} & \multirow{2}{*}{3.5} \\
\hline & $Y / Z$ & $0.0023^{\circ}$ & & & & & \\
\hline$B$ & $\begin{array}{l}X / Z \\
Y / Z\end{array}$ & $\begin{array}{l}0.0056^{\circ} \\
0.0072^{\circ}\end{array}$ & 32 & 1.2 & -1.6 & 2.2 & 3.8 \\
\hline
\end{tabular}

Table 1. Results from flatness analysis of lapped surfaces using the air bearing system (type $A$ ) and rigid bearing system (type $B$ ).

\section{CONCLUSIONS}

Tests were carried out to evaluate the surface quality obtained with an air bearing supported lap and to compare with results using a rigid bearing system. It was found that a rigid bearing system generates vibrations that have a negative effect on surface quality, especially on flatness and roughness, requiring longer lapping times than the air bearing supported lap to attain very high quality surfaces.

Step lapping appears to be a good alternative to improve the surface quality when single-face lapping is required, but its application depends strongly on the material to be lapped as well as on the surface finish specifications.

\section{ACKNOWLEDGEMENTS}

The authors are indebted to Mr. Rigoberto Nava for valuable discussions during the measurements at the Metrology Laboratory of the CCADET - UNAM.

\section{REFERENCES}

[1] Ascanio G, Cava C, Reséndiz R, Chicurel R, Nava, R. Rotating lapping machine with a neumatic bearing supported lap, Ann. ASPE 1997; 16; 283-286.

[2] Kackzmarek K. Principles of machining by cutting, abrasion and erosion. Warsaw: Peter Peregrinus, 1979, pp 414-424.

[3] Matsunaga M. Fundamental studies on lapping. Report of the Institute of Industrial Science, University of Tokyo, Japan, 1996.

[4] Peterson M, Le X, McKinley D. Monitoring of the Material Removal Rate in Flat Lapping. J Adv Materials 1998; v.30, n.4; 41-55.

[5] Lynah P. Lapping. Metals Handbook vol. 3. Ohio: ASM 1989, pp 298-310.

[6] Reséndiz R, Martinez A, Ascanio G, Galindo E, A new pneumatic bearing dynamometer for power input measurement in stirred tanks. Chem Eng Tech 1991; 14; 105-108.

[7] Bralia G. Honed, lapped and superfinished parts: Handbook of product design and manufacturing. USA: McGraw Hill, 1988, pp 4.169-4.179. 
[8] Cava C. Design and Characterization of a lapping machine with an air bearing supported lap (in Spanish), B.Sc. thesis, National Autonomous University of Mexico, Mexico City, 1998.

[9] Amstead P, Ostwald F, Begeman M. Manufacturing processes SI version (in Spanish), Mexico City: CECSA, 1981. pp 681-698.

[10] Slocum A. Aerostatic bearings. Precision machine design. USA: Prentice Hall, 1992, pp 580-607.

[11] Sugita T, Yamada H, Nishi M. A Study on Lapping Mechanism by Method of Visualization ( $1^{\text {st }}$ Report) $-A$ Method of Visualization and Investigation for Movement of Abrasive Grain in Lapping-. Int J Japan Soc Prec Eng 1997, v.31, n.3; 193-200.

[12] Kalpakjian S. Manufacturing Engineering and Technology. Reading, MA; Addison Wesley Longman, 1992. 


\section{Authors Biography}

\section{Gabriel Ascanio}

Got both the B.Sc. and the M.Sc. in Mechanical Engineering from Universidad Nacional Autónoma de México, UNAM in 1988 and 1995, respectively, and the Ph.D. in Chemical Engineering from Montreal Polytechnique School. Currently, he is a senior researcher at Centro de Ciencias Aplicadas y Desarrollo Tecnológico, UNAM (CCADET). His research interests lie on fluids and process engineering as well as on mechanical instrumentation.

\section{Carlos Cava}

Got the B.Sc in Mechanical Engineering from UNAM in 1998. He is currently a project engineer at General Motors Mexico.

\section{Ricardo Chicurel}

Received the B.Sc. in Mechanical Engineering in 1953 from Cornell University, and both the Master of Science in Engineering and Doctor of Engineering from Princeton University in 1957 and 1959, respectively. He was a professor of Engineering Mechanics at Virginia Polytechnic Institute and State University from 1959 to 1970 . Since 1970, he has been a researcher at the Instituto de Ingeniería, UNAM. He has six years of industrial experience.

\section{Roberto Reséndiz}

Got the B.Sc. in Mechanical Engineering from UNAM. Nowadays, he is the director of Pirámide Estructural del Golfo in Veracruz, Mexico. He is a specialist in machining processes and he has been working for several years in the development of oil pumping equipment for extraction platforms and power plants. 